\title{
Figurative Numbers Contribution in Perceiving the Legality in Numerous Strings Tasks and Long-term Memory of Numerous Data
}

\author{
Miroslava Mihajlov Carević ${ }^{1}$, Milena Petrović ${ }^{2 \star}$, Nebojša Denić ${ }^{2}$ \\ ${ }^{1}$ Faculty of Mathematics and Computer Science, Alfa BK University, Belgrade, SERBIA \\ 2 Faculty of Science and Mathematics, University of Priština, Kosovska Mitrovica, SERBIA
}

Received 12 April 2018 • Revised 25 December 2018 • Accepted 4 January 2019

\begin{abstract}
Contemporary mathematics teaching is mostly reduced to the application of algebraic formulas and algebraic procedures. The visual-logical approach in solving mathematical tasks is very little represented in teaching mathematics. Such practice should be changed since visualization is of great importance in the process of learning and understanding mathematics as well as in solving mathematical tasks. This paper suggests the possibility of developing students' ability to perceive lawfulness among numbers by introducing figurative numbers in mathematics teaching. Considering the visual presentation of figurate numbers and obvious rules among their members, students find them interesting and easy for understanding. They can also be a very good paradigms for many tasks with numerous arrays. The research carried out in this paper has shown that figurative numbers contribute to a visual-logical approach in solving tasks with numerous arrays and provide long-term storage of numerous data.
\end{abstract}

Keywords: figurative number, visualization of the solution, long-term memory of numerous data

\section{INTRODUCTION}

During many years of working with students we realized that the visual-logical approach in solving mathematical problems is insufficiently represented within mathematics teaching. In regular math classes a very small number of students are aware that linking the problem elements and observing the laws among them can lead to the solution of a given problem. Pupils are very little or not at all introduced with that kind of approach to solving tasks. Modern teaching of mathematics is mostly reduced to the application of algebraic formulas and algebraic procedures.

The research we conducted in secondary and elementary school in Belgrade, Serbia, has confirmed our empirical observations. When we asked first grade high school students to tell us what the sum of the first 1000 natural numbers is, we received only a few correct answers. In the second grade of high school, students are not more likely to solve similar tasks. Only in the third grade, when the arithmetic and geometric series are usually processed according to the curriculum, a large number of students will accurately calculate the sum of the first 1000 natural numbers, but only by applying the formula for the sum of the first $\mathrm{n}$ members of the arithmetic series. Visual-logical approach is very rarely applied in solving tasks with numerous arrays. Such practice should be changed because visualization and representation are of great importance in learning process and in understanding mathematics (Duval, 1999). They are also extremely useful, and sometimes necessary, in finding the solutions to the mathematical tasks (Arcavi, 2003).

In this paper we present the results of the research that is done with the first grade students of the gymnasium. The research covered 10 departments with a total of 297 pupils. At the beginning of the research, we carried out testing of the students in order to examine their ability to solve various tasks with natural numbers by observing laws. The results obtained at the pre-test were largely unsatisfying. Very few students accurately calculated the

(C) 2019 by the authors; licensee Modestum Ltd., UK. This article is an open access article distributed under the terms and conditions of the Creative Commons Attribution License (http://creativecommons.org/licenses/by/4.0/). $\square$ miroslava.carevic.mihajlov@alfa.edu.rs $\square$ milena.petrovic@pr.ac.rs (*Correspondence) 


\section{Contribution of this paper to the literature}

- In proposed research we confirm that the usage of the figurative numbers in solving mathematical problems develops students' ability of spotting the legality among the numbers.

- In this study we provide quantitative data analysis displaying the efficiency of successful solving of certain mathematical problems before and after introducing the students with some basic features of figurative numbers.

- We experimentally confirm that getting students acquainted with the figurative numbers and their legalities contributes to the longer term storage of numerous data in which certain legality exists.

sum of the first 1000 natural numbers. An even smaller number was able to determine the following three elements of a given array of numbers. That is why we introduced the first grade students with selected examples. In these examples we demonstrated the connection between the elements of the problem situation and its solution by applying the observed connection. A part of the planned lessons was realized by applying the GeoGebra software package. This way, selected examples were presented to the students in a more efficient way. In that manner they were led into a visual-logical approach to understanding the problem situation. We also wanted to maintain the continuity of their applications in the educational process by using modern teaching technologies (computers and software packages). The training of students for the active use of modern technologies is of the highest importance in contemporary education (Doruk, Aktumen \& Aytekin, 2013).

In order to compare the results after the completion of the research, we formed two groups of students, experimental and control, in which teaching was conducted differently. Students in the experimental group were introduced to figurative numbers, after which they independently or with the help of teachers observed the laws among the numbers and solved the set tasks. On the other hand, students in the control group weren't introduced to the figurative numbers. Still, we did demonstrate them the selected examples in which the observation of the legality among numbers and visual-logical approaches were used. Both groups are composed out of 5 departments with approximately the same number of students and nearly the same average grade in mathematics. In both groups, collaborative learning in small three-member groups was organized because it was recommended by educators as one of the most advanced tools for improving teaching and learning (Chai, Lin, So \& Cheah, 2011; Dooly, 2008). After the end of the planned classes, students of both groups were tested. The pre-test showed that there was no statistically significant difference between the experimental and the control group. In the post-test, the results of both groups were better than those on the pre-test. Still, the experimental group had better results than the control group and the difference between them was statistically significant.

Upon completion of the planned work with the students from both groups, the first check of the numerous data memorization was performed. The results in the experimental and control group were almost identical. After two weeks we checked the durability of the memorized numerical data. This time, the experimental group had significantly better results than the control.

During the selection of tools in the experimental group, for demonstrating the observation of legality among numbers, we chose the figurative numbers. We decided to take this choice, guided by the results of the researchers such as Beery (2009), Dickson (2013), Pengelley (2013), Braza and Tong (2001), Caglayan (2014). Consequentially, cited results envisaged us the potential possibility of applying the figurative numbers for demonstrating and developing the visual-logical approach in solving problems with numerous data. The results of our research confirm that the figurative numbers are a good choice for achieving this goal.

Our work consists of 7 sections. These sections are designed to familiarize the reader with the presence of figurative numbers in the mathematics teaching of the contemporary educational processes. We present in our work the methodology of this research, the obtained experimental results and the conclusions we came up with after the research ended.

\section{FIGURATIVE NUMBERS}

Figurative numbers were already present in mathematics and other scientific disciplines for 26 centuries. From the initial Pythagorean triangular, square and rectangular numbers, over time they have been supplemented with the whole class of polygonal, pyramidal, polyhedral and other figurative numbers. The figurative numbers can be described informally as numbers that can be represented by a regular algebraic form and a discrete geometric pattern with equally spaced points. If we look at polygonal numbers consisting of triangular, square, pentagonal, hexagonal and other $\mathrm{m}$-angular numbers, their algebraic formula by which all numbers of this type are generated are: $n \cdot(n+1) / 2 ; n^{2} ; n \cdot(3 n-1) / 2 ; n \cdot(2 n-1)$ respectively. Some of the triangular, square, pentagonal and the hexagonal number geometric interpretations are shown in Figure 1. 

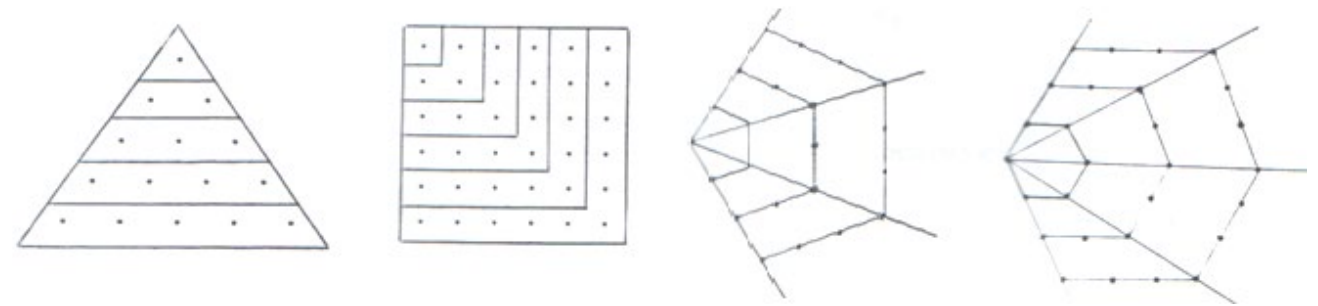

Figure 1. Triangular, square, pentagonal and hexagonal figurative numbers

The figurative way of writing numbers enables a visual observation of their features. This makes them suitable objects of operations. It is easy to understand why this way of showing numbers has been applied in ancient mathematics for centuries. These numbers have a simple definition, but they are incredibly rich in properties that allow them to be used in many areas of mathematics and other scientific disciplines. In the past centuries, many famous mathematicians dealt with them, from Pythagoras to Gauss (Deza \& Deza, 2012).

Also, in the modern age figurative numbers are the subject of many scientists' interest. Lancelot Hogben (1995) has proved that figurative series of order $(n+1)$ are completely determinable for all dimensions. Raphael Finkelstein (1972) dealt with the determination of triangular numbers which are the sums of successive squares. Michael Bennett (1997) found interesting conclusions by examining the equality of the $\mathrm{n}$-th tetrahedral number and the sum of $\mathrm{m}$ square numbers. Figurative numbers were also used to solve certain Diophantine equations (Brindza, Pinter \& Tyrjanyi, 1998; Hajdy, Pinter, Tengely \& Varga, 2014) and for the presentation of natural numbers using the sum of triangular, pentagonal and hexagonal numbers (Ono, Robins \& Wahl, 1995; Toh, 2013). Then, figurate numbers were used for the representation of natural numbers as the sum of the squares, the odd square and the triangular number (Oh \& Sun, 2009) and in many other issues.

Figurative numbers are associated with many classes of positive integer numbers such as binomial coefficients, Pythagorean triples of numbers, perfect numbers, Fibonacci numbers, and other numbers used in mathematics teaching. Their presence in contemporary science is multiple and indisputable as well as their connection with numerous mathematical fields. Therefore, the absence of the figurative numbers from regular math teaching in elementary and secondary education in Serbia is incomprehensible.

\section{CONTEMPORARY EDUCATIONAL PROCESSES}

One of the major features of contemporary society is the expansion of information and communication technologies. Therefore, training students for active use of modern technologies is one of the main education goals. This aim can be achieved by using the modern approaches based on new technologies in teaching process together with appropriate pedagogical methods (Manenova, Skutil \& Zikl, 2010; Abu Bakar, Ayub, Fauzi \& Tarmizi, 2010). The modern digital era requires modern teachers who are ready to use the modern technology and are able to apply them in the teaching process for the purpose of more effective teaching (Kim, 2002; Tabach, 2012; Ruthven, 2009). Some researches show that the use of information and communication technologies integrated into teaching activities has a positive impact on thinking process among the students by encouraging creative thinking (Alegra, Chifari \& Ottaviano, 2001; Viamonte, 2010).

The integration of modern technological achievements in teaching processes attracts the growing improvement of math teaching. New technologies have considerably expanded a set of teaching resources in education. Over the past decade there has been a rapid development of dynamic software packages, such as GeoGebra, Geometers' Sketchpad, Cabri Geometry. Many researchers confirmed the effectiveness of mathematical learning when the math software packages are applied (Bozkurt \& Ruthven, 2016; Figueira-Sampaio, Santos \& Carrijo, 2009; Hohenwarter, Hohenwarter \& Lavicza, 2009; Hohenwarter \& Fuchs, 2004; Lavicza \& Varga, 2010; Ruthven, Hennessy \& Deaney, 2008; Saha, Ayub \& Tarmizi, 2010; Takači, Stankov \& Milanovic, 2015; Zengin, Furkan \& Kutluca, 2012). Within this research we use the GeoGebra software package.

In this paper, we present a contemporary approach to introducing students with figurative numbers and selected examples to demonstrate the observation of lawfulness among numbers, based on collaborative learning with computer support. Today, this approach is considered as one of the most advanced approaches to improve learning and teaching (Gomez, Wu \& Passerini, 2010; Laal \& Ghodsi, 2012). 


\section{METHODOLOGICAL FRAMEWORK FOR RESEARCH}

\section{Problem of Research}

In the first grade high school one of the mathematical fields that is being studied, at the beginning of the first semester, is the field of the "Real Numbers". Regarding the real numbers, problems of number divisibility occurs, such as: "Show that the sum of all odd numbers smaller than 150 is divisible by 125 ". The main difficulty in this task is to determine the sum of these numbers because the students are not trained to solve such problems. Factoring the number and proving its divisibility with the required number works well because determining a divisor of a certain natural number was learned in the elementary school. But in this case, students lack the beginning of solving the problem, and hence a complete solution. Calculating the value of the expression

$100^{2}-99^{2}+98^{2}-972+\ldots+4^{2}-3^{2}+2^{2}-1^{2}$

is hard to complete for most of the students. Several students begin to solve this task by dividing the squares difference into factors, using their elementary school knowledge:

$(100-99) \cdot(100+99)+(98-97) \cdot(98+97)+\ldots+(4-3) \cdot(4+3)+(2-1) \cdot(2+1)$

after which they get the expression:

$1 \cdot 199+1 \cdot 195+1 \cdot 191+\ldots+1 \cdot 7+1 \cdot 3$, then they got the expression:

$199+195+191+\ldots+7+3$

Still, they couldn't calculate this whole sum.

By observing figurative numbers, we have come to the conclusion that introducing the students to these numbers and their basic features has contributed to the acquisition and encouragement of visual-logical thinking among the students. Even more, by adopting obvious and simply to understand figurate numbers characteristics, students easily develop visual problem-solving approach. Also, figurative numbers can be paradigms for many problems with number sequences in which the differences between the two adjacent members are a set of rules that contribute to solving the task (Mihajlov-Carević, Kopanja \& Denić, 2017). Paradigms are extremely useful in the learning process. They contribute to faster and easier problem solving by switching to the isomorphic problem whose solution is already known. If an example that can represent a number of other examples is found, the way to gain insight into problem resolution is significantly reduced and facilitated.

Knowledge upgrading is the individual process, but students realize it by interacting with teachers, other students and other subjects in the educational process. In that context, the work of students in cooperation groups, the exchange of opinions, discussions and explanations are out of main importance. The work of the teachers during the class is also of the great importance. The teacher prepares the class with the goal of easing the studying process for students. He demands out of students to analyze the given problem and to connect it with the problem to which they already know the solution. Constructivism is an approach to teaching and learning based on the assumption that a student creates an opinion about new knowledge and information by linking them to already existing knowledge. This approach improves students' intellectual development. It substitutes the memorizing in learning and it is an excellent alternative to traditional methods in education (Iran-Nejad, 1995). Advantages of constructivism in teaching practice are also pointed out by other authors (Garcia, 2013; Schcolnik, Kol \& Abarbanel, 2016; Mc Phail, 2015). Also, learning through solving problems in the education system is accepted as an effective paradigm of learning (Wang, Wu, Kinshuk \& Spector, 2013).

In this paper we present introducing the first grade grammar school students to the examples that can be paradigms for many problems with whom they are faced with during the education. They can also be a means of developing constructive thinking.

\section{Tasks and Goal of the Research}

The primary tasks in this research are getting the answers on the next research questions:

1) Are the first grade high school students learned to observe the legality among numbers when solving problems with numerous data and numerous sets?

2) Does the usage of the figurative numbers in solving math problems contribute the students to develop the ability of observing the legality among the numbers? Will they be then more capable to solve the certain math problems?

3) Does the spotting of the legality among the numbers contribute to the long term memory of numerous data in which the legality between numbers exists? 
The aim of the research in this paper is the examining and determining the contribution of figurative numbers to the development of the abilities in noticing legality between numbers and long-term memory of numerous data of the first grade high school students.

\section{Research Hypotheses}

The hypotheses in this study are as follows:

1) It is assumed that a very small number of students of the first grade high school will be able to solve tasks requiring the identification of legality among the numbers.

2) Working with figurative numbers contributes to student's observations of the legality among the numbers which leads them to the solution of the problem;

3) Getting acquainted students with the figurative numbers and their legalities will contribute to better and longer-term storage of data, whenever it is possible to see some legality.

\section{Research Methods and Instruments}

The research was conducted in Belgrade, Serbia. The target group was composed of students of the first grade of grammar school. The study covered 10 departments, a total of 297 students. During September 2016, all students were solving a pre-test with 2 assignments:

1) How much is the sum of the first 1000 natural numbers?

2) Write three more elements of the next series of numbers: 2, 4, 8, 14, 22, 32, 44.

The pre-test aimed to show the student's ability to notice the lawfulness among the numbers and apply them to solve the given tasks. The pre-test results are shown in Table 1.

Table 1. Results of the pre-test

\begin{tabular}{|c|c|c|c|c|c|c|c|}
\hline \multirow{2}{*}{ Department } & \multirow{2}{*}{$\begin{array}{l}\text { Total number of } \\
\text { students }\end{array}$} & \multicolumn{2}{|c|}{$\begin{array}{l}\text { The number of students } \\
\text { who solved exactly }\end{array}$} & \multicolumn{2}{|c|}{$\begin{array}{l}\text { The number of students } \\
\text { who solved partially }\end{array}$} & \multicolumn{2}{|c|}{$\begin{array}{c}\text { The number of students } \\
\text { who have not solved }\end{array}$} \\
\hline & & 1.task & 2.task & 1.task & 2.task & 1.task & 2.task \\
\hline $1_{1}$ & 30 & 4 & 6 & 10 & 9 & 16 & 15 \\
\hline 12 & 30 & 5 & 6 & 8 & 8 & 17 & 16 \\
\hline $1_{3}$ & 30 & 3 & 5 & 11 & 12 & 16 & 13 \\
\hline 14 & 29 & 4 & 6 & 12 & 10 & 13 & 13 \\
\hline 15 & 30 & 4 & 6 & 14 & 11 & 12 & 13 \\
\hline 16 & 29 & 3 & 7 & 12 & 9 & 14 & 13 \\
\hline 17 & 30 & 5 & 7 & 10 & 9 & 15 & 14 \\
\hline $1_{8}$ & 30 & 3 & 6 & 11 & 8 & 16 & 16 \\
\hline 19 & 29 & 4 & 5 & 13 & 10 & 12 & 14 \\
\hline $1_{10}$ & 30 & 3 & 6 & 10 & 8 & 17 & 16 \\
\hline
\end{tabular}

Out of the 297 first grade students, the first task was solved by only 38 students or $12.8 \%$, while 60 students solved the second assignment i.e. $20.2 \%$.

Derived results can be characterized as a proof to our hypothesis that only the small number of students will be able to solve the problems where spotting the legality among numbers is necessary. Particularly worrying fact is that this initial test was done by students of gymnasium, who traditionally receive the best pupils from the generation who finished elementary school.

Taking into account the average grades from math and the number of students in the departments, we formed an experimental and control group of students. From the students of the first 5 departments, $1_{1}-1_{5}$, we formed an experimental group with 149 pupils, while $1_{6}-1_{10}$ students were a control group with a total of 148 pupils. The average grade in math as well as the number of students in the groups was approximately the same. Based on the pre-test results in the experimental and control groups, small three-member groups for collaborative learning with different levels of mathematical knowledge were formed. Specially, we formed in $1_{4}, 1_{6}$ and $1_{9}$ classes two fourmember collaborative groups. Collaborative groups are highly effective in teaching process since group members help each other in learning. Many effective learning researchers recommend them (Kagan, 1994; Petrović \& Kontrec, 2017). In collaborative learning, students are not only responsible for their learning, but also for learning other members of the group. In each group there was at least one student who solved one or more than one assignments or two students who partially solved both. Formed groups are expected to have about the same knowledge and the ability to work with numbers. Students are allowed to form groups by their choices in accordance with the rules 
laid down in order to achieve the best possible cooperation between members of the group (Dogru \& Kalender, 2007).

In the first grade of the gymnasium, real numbers are processed during 7 hours of regular classes. Students of both groups had 4 hours in the classroom working in the usual way and 3 hours in the computer room where they were introduced with the figurative numbers and selected examples that demonstrate the observation of legality among the numbers.

\section{Working with an Experimental and Control Group}

For both groups of students, we prepared three-hour introduction with selected examples that demonstrates the link between elements of the problem situation and its solution by using the observed connection. For the visualization of selected examples in both groups, GeoGebra software package was selected. We chose this package because it is simple and easy to use. Displaying figurative numbers with points and drawings prepared for working with a control group is very easy to do in GeoGebra's graphical representation. We did not use the dynamics of the GeoGebra software package or its other features.

At the beginning of the first hour, the students of the experimental group briefly became acquainted with the Pythagorean number representation modes with the figures of the triangles, squares and rectangles. They are then introduced to the first 5 triangular numbers shown in Figure 2.
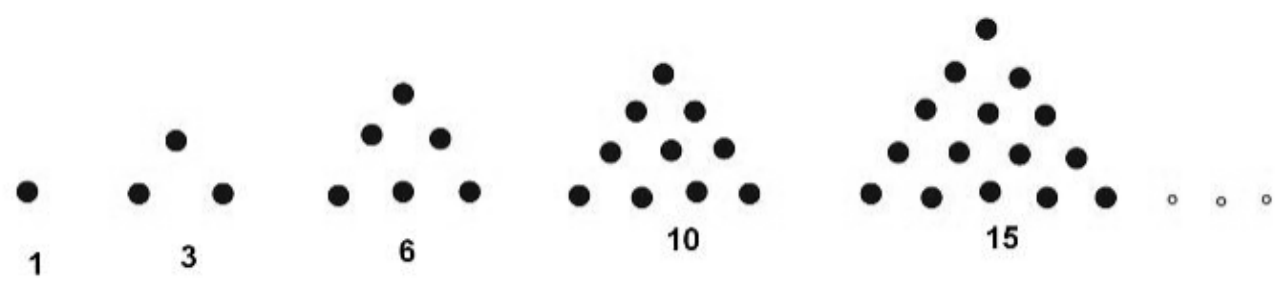

Figure 2. Display of triangular numbers

After that, the students were to determine the following triangular number and fill out the next table. After that, they calculate the differences between the triangular numbers and the differences between these differences:

Triangular numbers: $\quad \begin{array}{llllll}1 & 3 & 6 & 10 & 15\end{array}$ (enter the next triangular number)

Differences between them: $\begin{array}{llllllll}2 & 3 & 4 & 5\end{array}$ _ (enter the following difference)

Differen. between differences: 111 _ (enter the following differen. between differences)

Each group worked together on a task that was set up and the teachers kept a record of their answers. After that, we showed the students correct answer. Those who did not give the correct answers had a few minutes to conclude how to get it. The results of this part of the study are shown in Table 2.

Table 2. Results of first task solving in the experimental group

\begin{tabular}{lccccc}
\hline Department & $\mathbf{1}_{\mathbf{1}}$ & $\mathbf{1}_{\mathbf{2}}$ & $\mathbf{1}_{\mathbf{3}}$ & $\mathbf{1}_{\mathbf{4}}$ & $\mathbf{1}$ \\
\hline Groups & $1-10$ & $1-10$ & $1-10$ & $1-9$ & $1-10$ \\
\hline Number of correct answers & 5 & 6 & 4 & 5 & 5 \\
\hline
\end{tabular}

Then a second task was set up for the students. This time they were asked to solve the problem based on the beginning of triangular numbers series and the differences between them. After that, they should write another 5 elements in a series of differences and another 5 elements in a series of triangular numbers. In this way, the students are pointed to the path of thinking they need to go: the first difference should be recorded between the two triangular numbers, so that the next triangular number is obtained. This time, the groups were more successful in solving the task. The results are shown in Table 3.

Table 3. Result of second task in the experimental group

\begin{tabular}{lccccc}
\hline Department & $\mathbf{1}_{\mathbf{1}}$ & $\mathbf{1 2}$ & $\mathbf{1}_{\mathbf{3}}$ & $\mathbf{1}_{\mathbf{4}}$ & $\mathbf{1}$ \\
\hline Groups & $1-10$ & $1-10$ & $1-10$ & $1-9$ & $1-10$ \\
\hline Number of correct answers & 6 & 7 & 5 & 6 & 6 \\
\hline
\end{tabular}


During the second hour, pupils were familiar with square, pentagonal and hexagonal figurate numbers, after which they solved two tasks of the same content as in the triangular numbers problem. The graphs of pentagonal and hexagonal numbers (Figure 3) were of particular interest to them. It was noted that in several groups, students had points in the displayed image in GeoGebra, forming the following number in a row. Observing this, teachers suggested that all groups should do the same. The visual representation of the next issue in a series of pentagonal and hexagonal numbers additionally contributed to the creation of a correct student's opinion on how to form the next number in a series of figurative numbers.
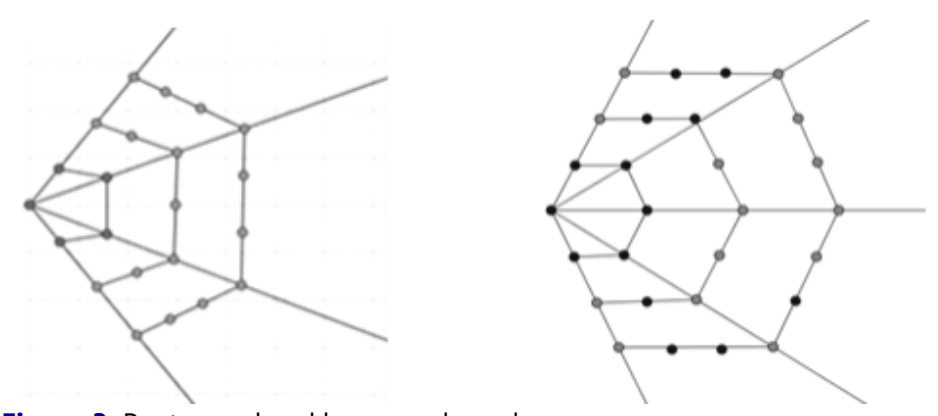

Figure 3. Pentagonal and hexagonal numbers

The results of determining the next quadratic number were probably the best because students were familiar with square numbers in the set of real numbers. It has been noted that the students determined them using the formula $x^{2}$ rather than using the triangular numbers and the difference between numbers or image views. In the case of pentagonal and hexagonal numbers, the students did not have any difficulty because they were already fit in the necessary way of thinking and perceiving the legality. The number of correct answers for each task per class is shown in Table 4.

Table 4. Number of correct answers received in all five departments of experimental group

\begin{tabular}{|c|c|c|c|c|c|c|c|c|c|c|}
\hline \multirow{3}{*}{$\begin{array}{l}\text { Department } \\
\text { Groups } \\
\text { Number of } \\
\text { correct answers }\end{array}$} & \multirow{2}{*}{\multicolumn{2}{|c|}{$\frac{11}{1-10}$}} & \multirow{2}{*}{\multicolumn{2}{|c|}{$\frac{12}{1-10}$}} & \multirow{2}{*}{\multicolumn{2}{|c|}{$\frac{13}{1-10}$}} & \multirow{2}{*}{\multicolumn{2}{|c|}{$\frac{14}{1-9}$}} & \multirow{2}{*}{\multicolumn{2}{|c|}{$\frac{15}{1-10}$}} \\
\hline & & & & & & & & & & \\
\hline & $\begin{array}{l}\text { First } \\
\text { task }\end{array}$ & $\begin{array}{l}\text { Second } \\
\text { task }\end{array}$ & $\begin{array}{l}\text { First } \\
\text { task }\end{array}$ & $\begin{array}{l}\text { Second } \\
\text { task }\end{array}$ & $\begin{array}{l}\text { First } \\
\text { task }\end{array}$ & $\begin{array}{l}\text { Second } \\
\text { task }\end{array}$ & $\begin{array}{l}\text { First } \\
\text { task }\end{array}$ & $\begin{array}{l}\text { Second } \\
\text { task }\end{array}$ & $\begin{array}{l}\text { First } \\
\text { task }\end{array}$ & $\begin{array}{c}\text { Second } \\
\text { task }\end{array}$ \\
\hline $\begin{array}{l}\text { Triangular } \\
\text { numbers }\end{array}$ & 5 & 6 & 6 & 7 & 4 & 5 & 5 & 6 & 5 & 6 \\
\hline Square numbers & 9 & 9 & 10 & 10 & 8 & 7 & 9 & 8 & 9 & 8 \\
\hline $\begin{array}{l}\text { Pentagonal } \\
\text { numbers }\end{array}$ & 7 & 9 & 8 & 9 & 5 & 6 & 7 & 8 & 7 & 8 \\
\hline $\begin{array}{l}\text { Hexagonal } \\
\text { numbers }\end{array}$ & 9 & 10 & 10 & 10 & 7 & 8 & 8 & 8 & 9 & 10 \\
\hline
\end{tabular}

During the work, teachers encouraged students to link a new task with the task known to them, ask questions and discuss how to solve the task and the solution obtained.

At the beginning of the third hour, students were asked to determine the 20th triangular number. All groups began to address this task using differences, as in the previous example. Several students commented that "there is a lot to account for". There were comments like" It's good that you did not look for a 200th triangular number". Then the students showed a procedure for determining the 20th triangular number shown in Figure 4. 


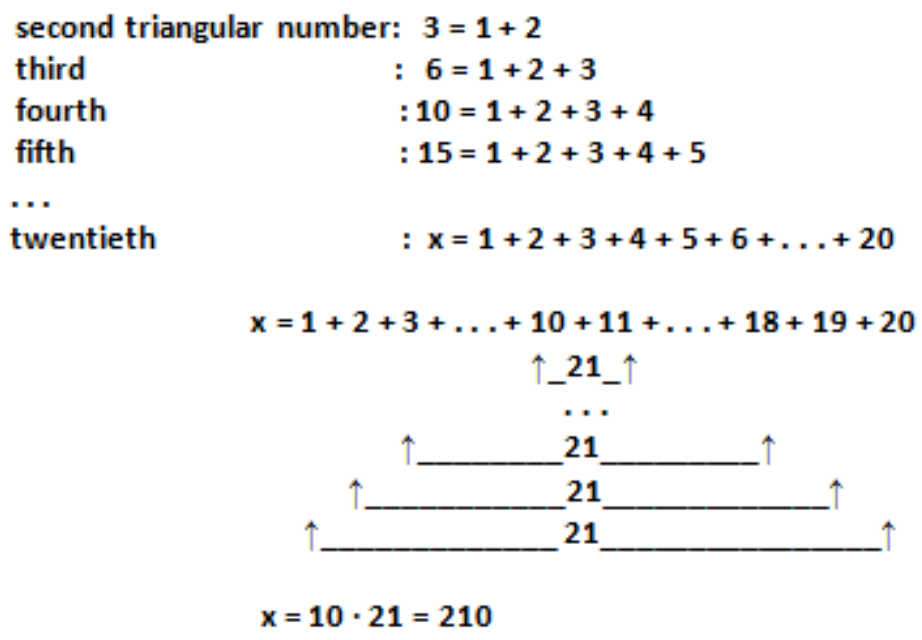

Figure 4. Determination of the twentieth triangular number

After that, the students solved the following tasks:

1) Determine the 33. triangular number.

During the task solving, the teachers discussed with members of the group and recorded their observations and responses. In all groups the students repeated the procedure from the previous solution, stating that the 33 . triangular number is equal to the sum

$1+2+3+4+5+\ldots+33$

but they had problems in determining this sum. Some of the students have computed in the way shown in Figure 5A and thinking that there are the 17 couples. They gave the next answer: $17 \cdot 34=578$, which is not correct. A small number of students wrote the central members of this collection, as shown in Figure $5 \mathbf{B}$ and concluded that the result was $16 \cdot 34+17=561$.

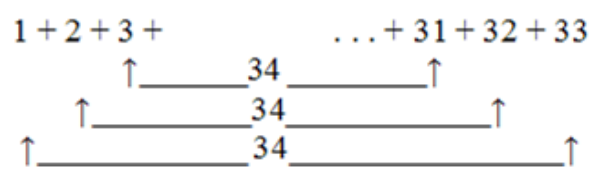

$5 \mathrm{~A}$

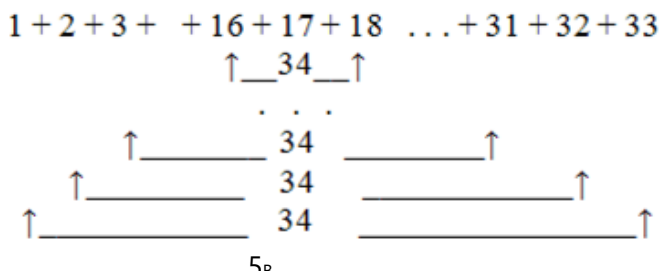

5 B

Figure 5. The procedure of determining the thirty-third triangular number

The results of solving this task are shown in Table 5.

Table 5. Number of exact answers in the first task

\begin{tabular}{lccccc}
\hline Department & $\mathbf{1}_{\mathbf{1}}$ & $\mathbf{1 2}$ & $\mathbf{1}_{\mathbf{3}}$ & $\mathbf{1}_{\mathbf{4}}$ & $\mathbf{\mathbf { 1 } _ { \mathbf { 5 } }}$ \\
\hline Groups & $1-10$ & $1-10$ & $1-10$ & $1-9$ & $1-10$ \\
\hline Number of exact answers & 4 & 5 & 3 & 3 & 4 \\
\hline
\end{tabular}

Pupils from groups who were accurately performed this task were asked to explain to the groups that did not get the exact result where they were mistaken. Then the students solved the following task:

2) Determine the 15. pentagonal number.

Using the example of determining the twelfth triangular number, the students determined the second, third, fourth, fifth pentagonal number but stopped in determining the fifteenth number. An example of such students' work is shown in Figure 6A. One member of the group has spotted that by adding 3 to the previous addend form all addends in a row, they calculated the fifteenth pentagonal number exactly, Figure $\mathbf{6 B}$ 


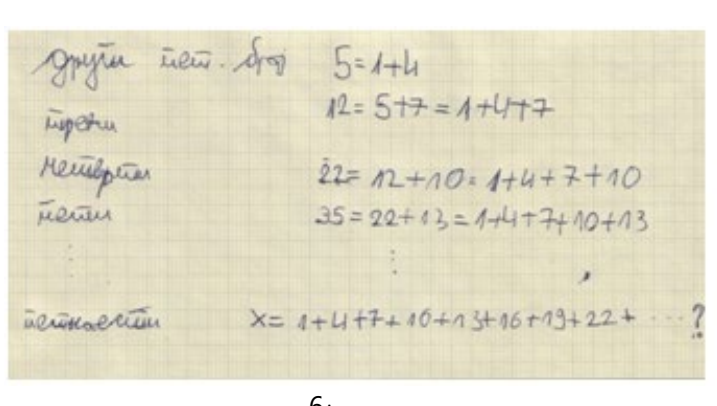

$6_{\mathrm{A}}$

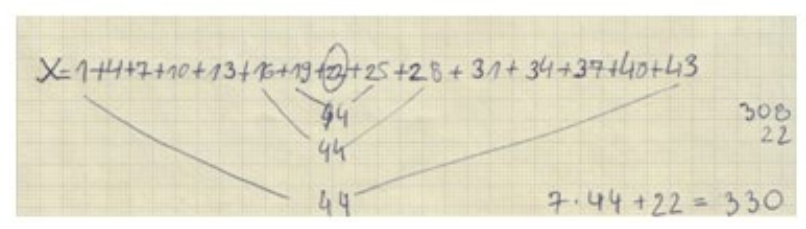

$6_{\text {B }}$

Figure 6. Students work

When their teacher asked them what they could do to calculate the 150. pentagonal number, they replied that it was not fair to ask them to compute such a large number and that they could not do it.

The results of solving this task are shown in Table 6.

Table 6. Number of exact answers in the second task

\begin{tabular}{lccccc}
\hline Department & $\mathbf{1}_{\mathbf{1}}$ & $\mathbf{1 2}_{\mathbf{2}}$ & $\mathbf{1 3}_{\mathbf{3}}$ & $\mathbf{1}_{\mathbf{4}}$ & $\mathbf{1}$ \\
\hline Groups & $1-10$ & $1-10$ & $1-10$ & $1-9$ & $1-10$ \\
\hline Number of exact answers & 7 & 8 & 5 & 5 & 6 \\
\hline
\end{tabular}

Then we showed the students that by using "Difference2" in pentagonal (and other) numbers, they can form "Differences1" by which they further form a series of these figurative numbers or calculate the required figurative number. The previous task was done as follows:

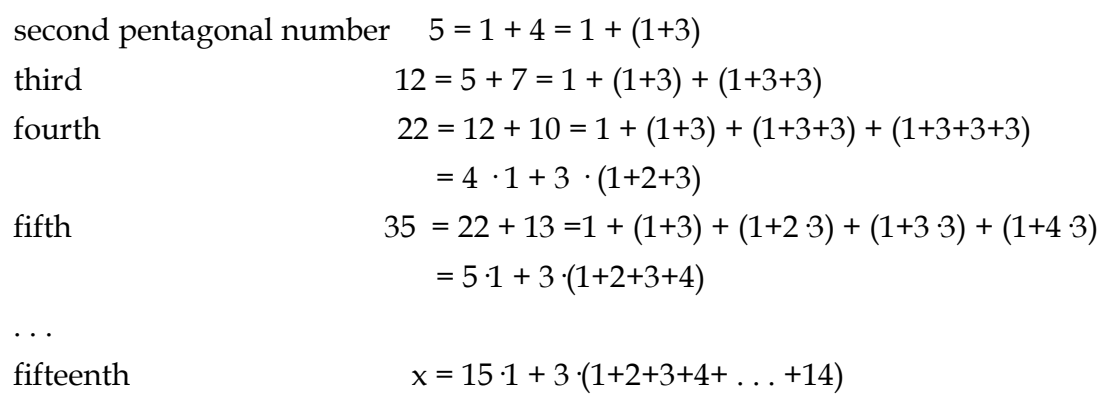

The calculation of the integer numbers from 1 to 14 is done in the manner shown above by grouping two numbers whose sum is 15 ( 1 and 14, 2 and 13, 7 and 8). Such pairs are a total of 7 so the sum of these numbers is equal to the value of the expression $7 \cdot 15=105$. The fifteenth pentagonal number is

$$
x=15+3 \cdot 105=330 .
$$

After that, students had a task that does not contain figurative numbers:

3) There is a array of numbers

$3,9,15,21,27,33,39 \ldots$

Determine the 80 . member of this series.

All groups started solving the task by noticing the difference between members of the series

$\begin{array}{lllllllllll}3 & 9 & 15 & 21 & 27 & 33 & 39 & \ldots & x_{79} & x_{80}\end{array}$

$\begin{array}{lllllllll}6 & 6 & 6 & 6 & 6 & 6 & \ldots & 6\end{array}$

Then most groups correctly solved the task in the following way

$\mathrm{x}_{2}=3+6$

$x_{3}=3+6+6$

$x_{4}=3+6+6+6$

...

$x_{80}=3+(6+6+6+\ldots+6)=3+79 \cdot 6=3+474=477$

$\leftarrow$ total $79 \rightarrow$

The results of solving this task are shown in Table 7. 
Table 7. Number of exact answers in the third task

\begin{tabular}{lccccc}
\hline Department & $\mathbf{1}_{\mathbf{1}}$ & $\mathbf{1}_{\mathbf{2}}$ & $\mathbf{1}_{\mathbf{3}}$ & $\mathbf{1}_{\mathbf{4}}$ & $\mathbf{1}_{\mathbf{5}}$ \\
\hline Groups & $1-10$ & $1-10$ & $1-10$ & $1-9$ & $1-10$ \\
\hline Number of exact answers & 9 & 10 & 9 & 9 & 10 \\
\hline
\end{tabular}

After this task, the work in the Informatics cabinet was completed, the students returned to regular classes where they had spent 4 hours, working individually, following lectures and exercises from real numbers.

Presented procedures and obtained scores confirm that the first grade high school students can independently solve tasks using the figurative numbers legalities, after the training. Even more, they are able to notice different laws among the numbers and to apply them, as a tool, for solving various problems.

During the first three hours we pointed to the students in the control group on visual-logical approach to problem-solving and troubleshooting. We were using selected examples in which we showed them how to observe the lawfulness among the numbers. They worked in collaborative groups, in the computer room, using computers, boards and chalk.

At the beginning of the first time, they were introduced to the Pythagorean procedure for determining the collection of odd numbers that was concretized and explained on the example:

$1+3+5+7+9+11$ (Figure 7A).

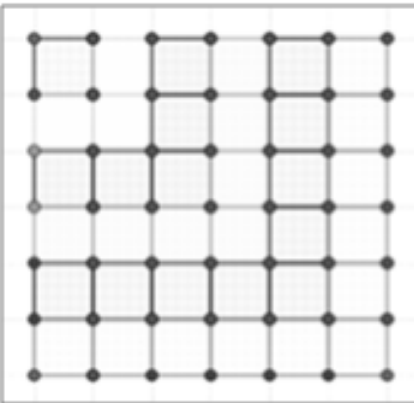

$7_{\mathrm{A}}$

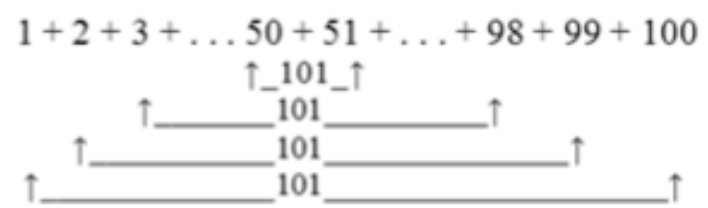

Solution: $1+2+3+\ldots+99+100=50 \cdot 101=5050$

Figure 7. Shows the collection of odd numbers and the Gaussian process

After that it was required to calculate the sum of the following numbers:

1) $1+3+5+7+\ldots+39$

2) The sum of all odd numbers smaller than 100 .

Throughout the course, teachers encouraged students to connect new tasks with the task whose solution is known, to ask questions and discuss ways of solving and obtaining the solution. The groups that solved the task helped other groups to come up with a solution.

At the beginning of the second semester, students are introduced to Gaussian calculations of the first 100 natural numbers (Figure 7B).

After that, students were required to calculate the following sums:

1) $1+2+3+\ldots+84+85$

2) A collection of all natural numbers smaller than 200.

Then the students were assigned to do the following task:

Determine the total number of square plates required for paving on one side of the staircase that has 19 steps. With the text of the task, students are shown a picture of the staircase on the screen (Figure 8A). After the scheduled time for solving this task, we showed the students a solution with the addition of a staircase in the reverse position, which gives a rectangle in which the total number of records is $19 \cdot 20$. Based on that case they could easily conclude that the number of panels 190 is required (Figure 8B). 


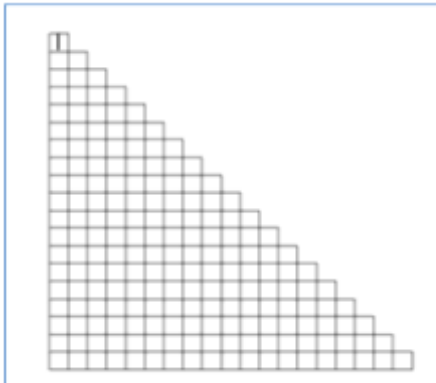

$8 \mathrm{~A}$

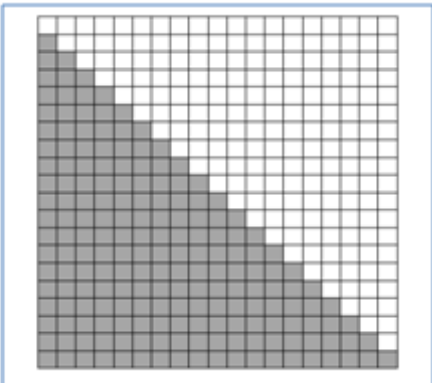

8 B

Figure 8. Stairway display

At the beginning of the third hour, students were presented with natural numbers divisible by 3 , then numbers divisible by 5 and numbers divisible by 7 :

$$
\begin{aligned}
& 3,6,9,12,15,18 \ldots \\
& 5,10,15,20,25,30 \ldots \\
& 7,14,21,28,35,42 \ldots
\end{aligned}
$$

In this case, it is presented a difference between two adjacent members in each row of numbers. Then students were required to form 10 members of the series whose first article is 2 and the difference between the two adjacent articles is 6 . Then the series whose first article is 8 and the difference between the two adjacent articles is 3 . After that, the following task was solved:

Observe the legitimacy of forming a given sequence of numbers and write down three more members:

a) $3,8,13,18,23,28 \ldots$

b) $1,2,4,7,11,16,22,29 \ldots$

During the time, teachers asked students to analyze their tasks and to associate them with tasks known to them. They helped the students to come up to the solution. Therewith, students who quickly understood the process of work helped other members of their group to progress.

With this task we finished exercising the observation of the legality among the numbers for the control group. The students returned to regular classes where they spent 4 hours, working individually, followed lectures and exercises from real numbers.

After the completion of the seven-hour work, all first-class students were doing test considering real numbers. The results of that test with analysis of students' performance are analyzed in the following section.

\section{RESULTS AND ANALYSIS OF THE TEST}

In this section, we present a statistical analysis of the pre-test and test based on student achievements. We measured these achievements by counting the number of correct answers and the achieved number of points on the tests. In both statistical analyzes, we applied Student's t-test difference between the arithmetic meanings of two large independent samples.

\section{Pre-test Results}

The pre-test was intended to demonstrate the first grade gymnasium students' ability to spot the legitimacy among the numbers and apply them to solve the given tasks. Based on the results obtained in Table 1, we obtained the answer of our first research question and we concluded that students were not learned to use such an approach in analyzing and solving tasks. The pre-test also showed that there was no statistically significant difference between the experimental and the control group.

Statistical pre-test results are shown in Table 8. Based on the average number of students' points (each correctly resolved task scored with 5 points and a partially solved task with 2.5 points) and calculated values for the arithmetic mean and standard deviation, a $t$-value of 0.459 was obtained. The resulting $t$-value is less than the threshold value for a significance threshold of 0.05 , indicating that the difference between the experimental and the control group is not statistically significant at the level of significance of 0.05 . 
Table 8. Statistical results of the pre-test

\begin{tabular}{lccccc}
\hline Group & $\begin{array}{c}\text { Number of } \\
\text { students }\end{array}$ & Arithmetic mean & Standard deviation & $\begin{array}{c}\text { Test the difference between arithmetic } \\
\text { means }\end{array}$ \\
\hline & & & & t-value & p (2-Tailed) \\
\hline Experimental & 149 & 3.41 & 0.232 & 0.459 & 0.685 \\
\hline Control & 148 & 3.34 & 0.250 & & \\
\hline
\end{tabular}

\section{Test Results}

Test problems were based on the legality between the numbers and their solutions give the answer on the second research question. These were the following tasks:

1) Show that the sum of all steam numbers smaller than 1000 is divisible by 499.

2) Calculate the following value:

$19992-1998^{2}+1997^{2}-1996^{2}+\ldots+3^{2}-2^{2}+1^{2}$.

Each of these two tasks was valued with a maximum of 5 points. The success of students in solving the first and second tasks is presented in Table 9.

Table 9. Number of points achieved in the first and second tasks

\begin{tabular}{ccccccccccccc}
\hline $\begin{array}{c}\text { Number of } \\
\text { points }\end{array}$ & $\mathbf{1}_{\mathbf{1}}$ & $\mathbf{1}_{\mathbf{2}}$ & $\mathbf{1}_{\mathbf{3}}$ & $\mathbf{1 4}_{\mathbf{4}}$ & $\mathbf{1}_{\mathbf{5}}$ & $\mathbf{\Sigma} \mathbf{E}$ & $\mathbf{1}_{\mathbf{6}}$ & $\mathbf{1}_{\mathbf{7}}$ & $\mathbf{1}_{\mathbf{8}}$ & $\mathbf{1 9}_{\mathbf{9}}$ & $\mathbf{1}_{\mathbf{1 0}}$ & $\mathbf{\Sigma}_{\mathbf{K}}$ \\
\hline $\mathbf{1 . t a s k}$ & & & & & & & & & & & 0 \\
\hline 0 & 0 & 0 & 0 & 0 & 0 & 0 & 0 & 0 & 0 & 0 & 0 & 0 \\
\hline 1 & 2 & 0 & 3 & 3 & 0 & 8 & 2 & 2 & 4 & 3 & 3 & 14 \\
\hline 2 & 1 & 3 & 6 & 4 & 6 & 20 & 4 & 5 & 5 & 6 & 9 & 29 \\
\hline 3 & 4 & 2 & 6 & 5 & 8 & 25 & 12 & 9 & 10 & 8 & 8 & 47 \\
\hline 4 & 12 & 11 & 7 & 8 & 7 & 45 & 7 & 8 & 6 & 6 & 4 & 31 \\
\hline 5 & 11 & 14 & 8 & 9 & 9 & 51 & 4 & 6 & 5 & 6 & 6 & 27 \\
\hline $\mathbf{2 .}$ task & & & & & & & & & & & & \\
\hline 0 & 0 & 0 & 0 & 0 & 0 & 0 & 0 & 0 & 0 & 0 & 0 & 0 \\
\hline 1 & 0 & 0 & 0 & 0 & 0 & 0 & 2 & 1 & 1 & 2 & 2 & 8 \\
\hline 2 & 0 & 0 & 0 & 0 & 0 & 0 & 3 & 6 & 3 & 4 & 2 & 18 \\
\hline 3 & 10 & 7 & 11 & 8 & 10 & 46 & 10 & 7 & 10 & 8 & 9 & 44 \\
\hline 4 & 12 & 14 & 11 & 13 & 13 & 63 & 11 & 12 & 12 & 10 & 11 & 56 \\
\hline 5 & 8 & 9 & 8 & 8 & 7 & 40 & 3 & 4 & 4 & 5 & 6 & 22 \\
\hline
\end{tabular}

From achieved results we can notice that in the both groups, none of the students have 0 points, either in the first or in the second task. Students in the experimental group achieved a total of 558 points in the first task, or 3.75 points per student, and 590 points or 3.96 per student in the second task. Pupils of the control group achieved a total of 472 points in the first task, or 3.19 per student, and in the second task 510 points or 3.45 per student.

In order to solve the first test task, it was necessary to calculate the sum of the numbers

$2+4+\ldots+996+998$

which amounts to 249500 , and this is a number that is divisible by 499 , which makes this task solved. The process of collecting a series of numbers with a certain legality among the members was shown to both groups (as described above) and practiced in several tasks.

When solving the second task, after decomposing a given expression to free factors, the term is given

$3997+3993+3989+\ldots+9+5+1$

which is solved as the previous task. The process of solving both tasks was practiced in both groups during the three-hour exercise.

By comparing the results achieved in these tasks, it is noted that the experimental group was more successful than the control group. The difference in their performance is statistically significant, as shown in the statistical results in Table 10. 
Table 10. Statistical results of the test

\begin{tabular}{lccccc}
\hline Group & $\begin{array}{c}\text { Number of } \\
\text { students }\end{array}$ & Arithmetic mean & Standard deviation & $\begin{array}{c}\text { Test the difference between arithmetic } \\
\text { means }\end{array}$ \\
\hline & & & & t-value & $\mathrm{p}(2-$ Tailed $)$ \\
\hline Experimental & 149 & 7.70 & 0.347 & 6.760 & 0.000 \\
\hline Control & 148 & 6.63 & 0.071 & & \\
\hline
\end{tabular}

The obtained $t$-value is greater than the threshold value for a significance threshold of 0.05 , which shows that the difference in the average number of points achieved in the experimental and control group in the analyzed test tasks is statistically significant at the level of significance of 0.05 , i.e. $t(295)=6.760, p=0.000$.

In the first test task, it was necessary to calculate the sum of all steam of numbers smaller than 1000 . This is analogous to the first pre-test task, in which we asked the students to determine the collection of the first 1000 natural numbers. All students who did the test correctly were scored with 4 or 5 points (depending on whether they showed the divisibility of the obtained result with 499). Summarizing the students' success in determining the above sums of numbers, we concluded that in the experimental group the first task on the pre-test was solved by 20 and on the test by 96 students. In the control group, the first task on the pre-test was solved 18 and on the test 58 students.

The difference between the average value of the final and the initial state of the exact number of solutions in the first task, in the experimental group is 0.51 , while in the control group is 0.27 . These results indicate that the average efficiency of the first experimental factor, where working with figurative numbers was taken, is greater than the average efficiency of work without figurative numbers. Also, obtained results show that working with the figurative numbers contributes to developing the ability of observation considering legality among the numbers and therewith more successfully solving this type of problems.

After a three-hour exercise of a visual-logical approach in solving tasks with numerous strings of different instruments, both groups, experimental and control, made progress. This shows that figurative numbers are not the only instrument that increases the students' ability to perceive legality among numbers and apply observed laws in solving tasks. Still, it is certainly more effective than some other experimental factors applied in our research.

\section{LONGEVITY OF MEMORIZING NUMERICAL DATA}

A few days after we tested the students, the first check of the numerous data memory was performed. The teachers told the students the following:

"The number of registered dogs in the world is 171319253137. Try to remember this number."

After 5 minutes, a check of the stored number was performed. The students were given the papers in which they had written the memorized number. Results in all departments were good and are shown in Table 11.

Table 11. Percentage of the success of memorizing numerical data immediately after memorization

\begin{tabular}{|c|c|c|c|c|c|c|c|c|c|c|}
\hline Department & 11 & 12 & 13 & 14 & 15 & 16 & 17 & 18 & 19 & $1_{10}$ \\
\hline Number of pupils & 28 & 28 & 29 & 28 & 29 & 28 & 29 & 29 & 28 & 28 \\
\hline $\begin{array}{l}\text { Number of correct } \\
\text { answers }\end{array}$ & 28 & 28 & 28 & 28 & 29 & 27 & 29 & 28 & 28 & 27 \\
\hline $\begin{array}{l}\text { Percentage of correct } \\
\text { answers }\end{array}$ & $100 \%$ & $100 \%$ & $97 \%$ & $100 \%$ & $100 \%$ & $96 \%$ & $100 \%$ & $97 \%$ & $100 \%$ & $96 \%$ \\
\hline
\end{tabular}

Immediately after memorization, students from all groups gave almost a 100 percent true answer. After two weeks, the length of the stored data was checked. Teachers distributed papers to the students. They were told to enter the number of registered dogs in the world, i.e. the same task that was told them to do two weeks ago. Students' comments were something like:

"Uh, who could remember that?"

"I only remember that it was a huge number."

"I do not even remember how it started."

"I think it started with 1."

The results were completely different. (Students who did not attend the first check of numerical data are not included in this additional check.) The results are given in Table 12. 
Table 12. Percentage of the success of memorizing numerical data two weeks after memorization

\begin{tabular}{|c|c|c|c|c|c|c|c|c|c|c|}
\hline Department & 11 & $11_{2}$ & 13 & $11_{4}$ & $11_{5}$ & 16 & 17 & 18 & 19 & $1_{10}$ \\
\hline Number of pupils & 27 & 28 & 28 & 27 & 28 & 27 & 28 & 28 & 27 & 28 \\
\hline $\begin{array}{l}\text { Number of correct } \\
\text { answers }\end{array}$ & 25 & 28 & 25 & 26 & 27 & 14 & 13 & 12 & 13 & 12 \\
\hline $\begin{array}{l}\text { Percentage of correct } \\
\text { answers }\end{array}$ & $93 \%$ & $100 \%$ & $89 \%$ & $96 \%$ & $96 \%$ & $52 \%$ & $46 \%$ & $43 \%$ & $48 \%$ & $43 \%$ \\
\hline
\end{tabular}

When the students wrote their answers and handed them over, the teachers wrote the correct answer on the board. Students who did not remember the number they stored two weeks ago had following comments:

"I only remember that there were several billion registered dogs."

"Who can remember such numbers?"

Students who remembered the number of registered dogs in the world after two weeks had the same explanation. They noted the lawfulness of the numbers 171319253137 (each two adjacent numbers differ by 6) and the solution was easily reconstructed:

$$
\begin{aligned}
& \begin{array}{lllllll}
1 & 7 & 13 & 19 & 25 & 31 & 37
\end{array} \\
& +6+6+6+6+6+6
\end{aligned}
$$

Analyzing the results in the experimental and control group, we can notice that immediately after the memory of numerous data, the percentage of the success of reconstruction of the recorded data in the experimental group was $99.4 \%$, and in the controlling $97.8 \%$. Two weeks after, the percentage of success in the experimental group was $94.8 \%$, while in the control group it decreased to $46.8 \%$. The difference in the success of reconstruction of the stored data is graphically shown in Figure 9.

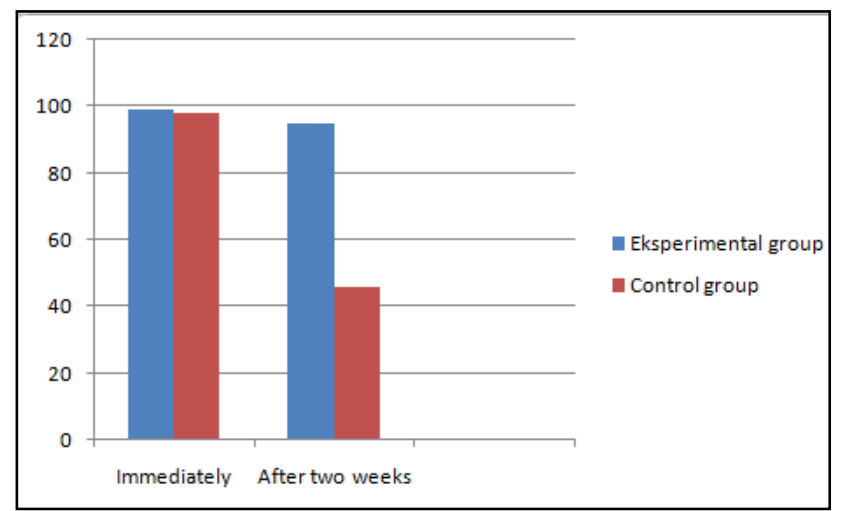

Figure 9. Percentage of success of memorizing numerical data

By examining the interrelation between the longevity of the memorized numerical data and the success of the students in the first and second test tasks, the correlation coefficient (Spiren coefficient) is $\rho=0.702$, which shows a marked connection between these variables.

\section{CONCLUSION}

In our research, we analyzed how students' knowledge of figurative numbers contributes to improving students' ability in perceiving legitimacy among numbers. Based on observed laws, as a consequence, students are able then to solve given problems more successfully. We also analyzed how the ability to detect legality affects the memory process and the longevity of the stored data.

Using computers and working in collaborative groups is not a novelty in mathematics teaching. We used mentioned technologies in this research since their application in the teaching process provides evidences of effectiveness. Getting acquainted with figurative numbers via computer and GeoGebra had an additional goal activating students to efficiently use information and communication technologies. The work of students in collaborative groups has helped each student to understand new concepts and apply learned to solve tasks. By joint incentives, when discussing the work process, during which they saw that one's opinion was good (or not good), students came to know each other with common forces that are always greater than the individual. 
Based on the results obtained in this research we can conclude that:

1) The first grade high school students are not thought to solve the problems with numerous data by observing the legality among the numbers;

2) Working with figurative numbers contributes to developing student's ability to observe the legality among the numbers. This way, students are trained to more successfully solve the problems in which spotting the legality between the numbers is necessary;

3) Observing the legality between the numbers contributes to the longer-term memory of numerous data among which certain legality exists.

Figurative numbers are closely related to many classes of positive integers, such as binomial coefficients, Pythagorean triplets of numbers, perfect numbers, Fibonacci numbers and other numbers used in mathematics teaching. Therewith, based on exposed research results, we conclude that continuing with this project of introducing figurative numbers into regular math classes for primary and secondary school is more then justified.

\section{ACKNOWLEDGEMENTS}

This paper is supported by the Ministry of Science of Republic of Serbia, Grant No. 174025.

\section{REFERENCES}

Allegra, M., Chifari, A., \& Ottaviano, S. (2001). ICT to train students towards creative thinking. Educational Technology \& Society, 4(2), 48-53.

Arcavi, A. (2003). The role of visual representations in the learning of mathematics. Educational studies in mathematics, 52(3), 215-241. https:/ / doi.org/10.1023/A:1024312321077

Bakar, K. A., Ayub, A. F. M., \& Tarmizi, R. A. (2010). Utilization of computer technology in learning transformation. International Journal of Education and Information Technologies, 4(2), 91-99.

Beery, J. L. (2009). Formulating figurate numbers. BSHM Bulletin: Journal of the British Society for the History of Mathematics, 24(2), 78-91. https:/ / doi.org/10.1080/17498430902820879

Bennett, M. A. (1997). Effective measures of irrationality for certain algebraic numbers. Journal of the Australian Mathematical Society, 62(3), 329-344. https:/ / doi.org/10.1017/S144678870000104X

Bozkurt, G., \& Ruthven, K. (2017). Classroom-based professional expertise: A mathematics teacher's practice with technology. Educational Studies in Mathematics, 94(3), 309-328. https:/ / doi.org/10.1007/s10649-016-9732-5

Braza, P. A., \& Tong, J. (2001). 85.25 Square-triangular numbers, revisited. The Mathematical Gazette, 85(503), 270273. https://doi.org/10.2307/3622015

Brindza, B., Pintér, Á., \& Turjányi, S. (1998). On equal values of pyramidal and polygonal numbers. Indagationes Mathematicae, 9(2), 183-185. https:/ / doi.org/10.1016/S0019-3577(98)80016-5

Caglayan, G. (2014). Visualizing number sequences: Secondary preservice mathematics teachers' constructions of figurate numbers using magnetic color cubes. The Journal of Mathematical Behavior, 35, 110-128. https:/ / doi.org/10.1016/j.jmathb.2014.06.004

Chai, C. S., Lim, W. Y., So, H. J., \& Cheah, H. M. (2011). Advancing collaborative learning with ICT: Conception, cases and design. Retrieved from http://ictconnection.edumall.sg/ictconnection/slot/u200/mp3/ monographs/advancing\%20collaborative,2

da Silva Figueira-Sampaio, A., dos Santos, E. E. F., \& Carrijo, G. A. (2009). A constructivist computational tool to assist in learning primary school mathematical equations. Computers $\mathcal{E}$ Education, 53(2), 484-492. https:/ / doi.org/10.1016/j.compedu.2009.03.012

Deza, M. M., \& Deza, E. (2012). Figurate numbers. World Scientific. https:/ / doi.org/10.1142/8188

Dickson, L. E. (2013). History of the theory of numbers: Diophantine Analysis (Vol. 2). Courier Corporation.

Dogru, M., \& Kalender, S. (2007). Applying the Subject" Cell" through Constructivist Approach during Science Lessons and the Teacher's View. Online Submission, 2(1), 3-13.

Dooly, M. (Ed.). (2008). Telecollaborative language learning: A guidebook to moderating intercultural collaboration online. Peter Lang.

Doruk, B. K., Aktümen, M., \& Aytekin, C. (2013). Pre-service elementary mathematics teachers' opinions about using GeoGebra in mathematics education with reference to 'teaching practices'. Teaching Mathematics and its Applications: An International Journal of the IMA, 32(3), 140-157. https:/ / doi.org/10.1093/teamat/hrt009 
Duval, R. (1999). Representation, Vision and Visualization: Cognitive Functions in Mathematical Thinking. Basic Issues for Learning.

Finkelstein, R., \& London, H. (1972). On triangular numbers which are sums of consecutive squares. Journal of Number Theory, 4(5), 455-462. https:/ / doi.org/10.1016/0022-314X(72)90036-4

Garcia, I., \& Pacheco, C. (2013). A constructivist computational platform to support mathematics education in elementary school. Computers \& Education, 66, 25-39. https:/ / doi.org/10.1016/j.compedu.2013.02.004

Gomez, E. A., Wu, D., \& Passerini, K. (2010). Computer-supported team-based learning: The impact of motivation, enjoyment and team contributions on learning outcomes. Computers E Education, 55(1), 378-390. https:/ / doi.org/10.1016/j.compedu.2010.02.003

Hajdu, L., Pintér, Á., Tengely, S., \& Varga, N. (2014). Equal values of figurate numbers. Journal of Number Theory, 137, 130-141. https:/ / doi.org/10.1016/j.jnt.2013.10.017

Hogben, L. (1954). Figurate Series and Factorial Notation. Human Heredity, 5(2), 115-133. https:/ / doi.org/10.1159/000150768

Hohenwarter, J., Hohenwarter, M., \& Lavicza, Z. (2009). Introducing dynamic mathematics software to secondary school teachers: The case of GeoGebra. Journal of Computers in Mathematics and Science Teaching, 28(2), 135146.

Hohenwarter, M., \& Fuchs, K. (2004, July). Combination of dynamic geometry, algebra and calculus in the software system GeoGebra. In Computer algebra systems and dynamic geometry systems in mathematics teaching conference.

Iran-Nejad, A. (1995). Constructivism as substitute for memorization in learning: Meaning is created by learner. EDUCATION-INDIANAPOLIS-, 116, 16-16.

Kagan, S. (1994). Cooperative learning. San Clemente, CA: Resources for Teachers, Inc..

Kim, C. Y. (2002). Teachers in digital knowledge-based society: new roles and vision. Asia Pacific Education Review, 3(2), 144-148. https:/ / doi.org/10.1007/BF03024907

Laal, M., \& Ghodsi, S. M. (2012). Benefits of collaborative learning. Procedia-social and behavioral sciences, 31, 486-490. https://doi.org/10.1016/j.sbspro.2011.12.091

Lavicza, Z., \& Papp-Varga, Z. (2010). Integrating GeoGebra into IWB-equipped teaching environments: preliminary results. Technology, Pedagogy and Education, 19(2),245-252. https:/ / doi.org/10.1080/1475939X.2010.491235

Maněnová, M., Skutil, M., \& Zikl, P. A. V. E. L. (2010). Taking advantage of ITC by teachers at the primary school. In Proc. of the 6th Educational technologies (EDUTE'10): WSEAS/IASME international conference. Athens: WSEAS (pp. 48-52).

McPhail, G. (2016). The fault lines of recontextualisation: The limits of constructivism in education. British Educational Research Journal, 42(2), 294-313. https:/ / doi.org/10.1002/berj.3199

Mihajlov-Carević, M., Kopanja, L., \& Denić, N. (2017). Figurative numbers as a tool for presentation paradigms and development constructive opinions. A collection of papers from the National Conference with international participation, Čačak: ITOP (pp.217-224).

Oh, B. K., \& Sun, Z. W. (2009). Mixed sums of squares and triangular numbers (III). Journal of Number Theory, 129(4), 964-969. https:/ / doi.org/10.1016/j.jnt.2008.10.002

Ono, K., Robins, S., \& Wahl, P. T. (1995). On the representation of integers as sums of triangular numbers. In Aggregating clones, colors, equations, iterates, numbers, and tiles (pp.73-94). Birkhäuser Basel. https:/ / doi.org/10.1007/978-3-0348-9096-0_6

Pengelley, D. (2013). Figurate numbers and sums of numerical powers: Fermat, Pascal, Bernoulli. Convergence, Mathematical Association of America. https:/ / doi.org/10.4169/loci003987

Petrović M. \& Kontrec, N. (2017). Possibilities for applying team teaching system in order to improve the efficiency of math teaching, A collection of papers from the National Conference with international participation, Leposavić: Innovation in education-digitalization,innovation models and programs.

Ruthven, K. (2009). Towards a naturalistic conceptualisation of technology integration in classroom practice: The example of school mathematics. Éducation et didactique, 3(1), 131-159. https:/ / doi.org/10.4000/educationdidactique.434

Ruthven, K., Hennessy, S., \& Deaney, R. (2008). Constructions of dynamic geometry: A study of the interpretative flexibility of educational software in classroom practice. Computers $\mathcal{E}$ Education, 51(1), 297-317. https://doi.org/10.1016/j.compedu.2007.05.013

Saha, R. A., Ayub, A. F. M., \& Tarmizi, R. A. (2010). The effects of GeoGebra on mathematics achievement: enlightening coordinate geometry learning. Procedia-Social and Behavioral Sciences, 8, 686-693. https://doi.org/10.1016/j.sbspro.2010.12.095 
Schcolnik, M., Kol, S., \& Abarbanel, J. (2016). Constructivism in theory and in practice. In English teaching forum (Vol. 44, No. 4, pp. 12-20). US Department of State. Bureau of Educational and Cultural Affairs, Office of English Language Programs, SA-5, 2200 C Street NW 4th Floor, Washington, DC 20037.

Tabach, M. (2012). A mathematcs teacher's practice in a tehnological environment: A case study analysis using two complementary theories. Technology, Knowledge and Learning, 16(3), 247-265.

Takači, D., Stankov, G., \& Milanovic, I. (2015). Efficiency of learning environment using GeoGebra when calculus contents are learned in collaborative groups. Computers $\mathcal{E}$ Education, 82, 421-431. https:// doi.org/10.1016/j.compedu.2014.12.002

Toh, P. C. (2013). On representations by figurate numbers: a uniform approach to the conjectures of Melham. International Journal of Number Theory, 9(04), 1055-1071. https:/ / doi.org/10.1142/S1793042113500127

Viamonte, A. J. (2010). The computer in the teaching of mathematics. In Proceeding of advanced educational technologies. 6th WSEAS/IASME international conference on educational technology (EDUTE'10) (pp. 24-29).

Wang, M., Wu, B., Chen, N. S., \& Spector, J. M. (2013). Connecting problem-solving and knowledge-construction processes in a visualization-based learning environment. Computers $\mathcal{E}$ Education, 68, 293-306. https://doi.org/10.1016/j.compedu.2013.05.004

Zengin, Y., Furkan, H., \& Kutluca, T. (2012). The effect of dynamic mathematics software geogebra on student achievement in teaching of trigonometry. Procedia-Social and Behavioral Sciences, 31, 183-187. https:// doi.org/10.1016/j.sbspro.2011.12.038

\section{http://www.ejmste.com}

